\title{
Selective Imidazoline Receptor Agonists: redefining the role of centrally acting agents in management of hypertension
}

\author{
Sadanand Shetty ${ }^{*}$, Anil Bhoraskar², J. C. Mohan ${ }^{3}$, Deodatta Chafekar ${ }^{4}$, \\ K. Tripathi ${ }^{5}$, M. Sivalingam ${ }^{6}$, Bhupen Desai ${ }^{7}$, Dilip Gude ${ }^{8}$, G. Sridhar ${ }^{9}$, Chacko Varghese ${ }^{10}$, \\ V.T. Shah ${ }^{11}$, Ramesh Dargad ${ }^{12}$
}

\begin{abstract}
${ }^{1}$ Consultant Cardiologist, Dr. Sadanand Shetty Clinic, Sitaram Bhavan, Mumbai, Maharashtra, India
${ }^{2}$ Consultant Diabetologist, Balchandra Niwas, Dadar, Mumbai, Maharashtra, India

${ }^{3}$ Department of cardiology and Sr. consultant cardiology at Fortis Hospital, Shalimar Bagh, Delhi, India

${ }^{4}$ Consultant Nephrologist, Shri Samarth Hospital, Sharangpur, Nasik, Maharashtra, India

${ }^{5}$ Consultant Nephrologist, Delhi Heart and Lung Institute in Mandir Marg, Delhi, India

${ }^{6}$ Department of Nephrologist, Sundaram Medical Foundation, Chennai, Tamil Nadu, India

${ }^{7}$ Consultant Cardiologist, Bhupen Desai, Bandra West, Mumbai, Maharashtra, India

${ }^{8}$ Department of Diabetologist, Vrinchi Hospital, Mumbai, Maharashtra, India

${ }^{9}$ Consultant Nephrologist, Global Hospital, Hyderabad, India

${ }^{10}$ Consultant Nephrologist, Jubilee Memorial Hospital, Thiruvananthapuram, Kerala, India

${ }^{11}$ Consultant Physician, VT Shah clinic, Sion, Mumbai, Maharashtra, India

${ }^{12}$ Consultant Physician, Mukund Hospital, Andheri-East, Mumbai, Maharashtra, India
\end{abstract}

Received: 04 July 2019

Revised: 07 September 2019

Accepted: 12 September 2019

\section{*Correspondence:}

Dr. Sadanand Shetty,

E-mail: drsadanand92@gmail.com

Copyright: (C) the author(s), publisher and licensee Medip Academy. This is an open-access article distributed under the terms of the Creative Commons Attribution Non-Commercial License, which permits unrestricted non-commercial use, distribution, and reproduction in any medium, provided the original work is properly cited.

\section{ABSTRACT}

Hypertension, often referred to as 'The silent killer', is christened so, as it is seldom preceded by any warning signs or symptoms. With the new ACC/AHA guidelines lowering the Blood Pressure (BP) threshold values, it has resulted in a $140 \%$ relative increase in the hypertension prevalence in India, which is 3 times higher than that of in United States. Imidazoline receptor agonists control BP effectively with minimal adverse effects of sedation and mental depression that are usually associated with centrally acting antihypertensives. While having a low affinity to the $\alpha 2$-adrenergic receptors, these new generation centrally acting antihypertensive agents are highly selective for imidazoline receptor. Moxonidine, a second-generation centrally acting antihypertensive drug having selective agonist activity on imidazoline $I_{1}$ receptors and minor activity on imidazoline $\alpha 2$ adrenoceptors, reduces the activity of Sympathetic Nervous System (SNS) by activating $\mathrm{I}_{1}$ imidazoline receptors in Rostral Ventrolateral Medulla (RVLM). Studies of moxonidine have shown equal effectiveness in lowering BP like other well-established antihypertensive drugs such as nifedipine, atenolol or angiotensin-converting enzyme inhibitors, with minimal adverse events. At doses of 0.2-0.6 $\mathrm{mg}$, moxonidine induces satisfactory BP reduction in patients with mild-to-moderate essential hypertension. In patients with mild-to-moderate hypertension, moxonidine (0.2-0.4 mg o.d.) significantly decreased Systolic Blood Pressure/Diastolic Blood Pressure (SBP/DBP), respectively, by $19.5 / 11.6 \mathrm{mmHg}$. In obese, non-controlled hypertensive patients, there is a $14 \%$ and $13.5 \%$ reduction in the mean SBP and DBP, respectively, from the baseline value after moxonidine treatment and during the follow-up with an additional reduction in body weight, plasma leptin levels and Body Mass Index (BMI) $(\mathrm{p}<0.01)$. Thus, moxonidine could be considered as a therapeutic option in obese patients with metabolic syndrome.

Keywords: Blood pressure, Metabolic syndrome, Moxonidine, Selective Imidazoline Receptor Agonists, Sympathetic activity 


\section{INTRODUCTION}

\section{Hypertension - a growing epidemic}

Hypertension is often referred to as the 'silent killer' in the medical terminology because there are no warning signs or symptoms caused by high Blood Pressure (BP) of its presence. ${ }^{1}$ At least $45 \%$ of deaths due to heart diseases, $51 \%$ of deaths due to stroke, and an estimated $16.5 \%$ (9.4 million) of all deaths annually are due to hypertension. BP values vary greatly and tend to increase with age in the people. The risk of vascular complications linearly increases with higher BP values. The hemodynamic factors involved in BP regulation include cardiac output, total peripheral resistance, stroke volume, and heart rate and at least four systems are responsible for direct BP regulation, which include the cardiac system, renal system, and blood vessel tone. ${ }^{2}$

\section{Implications of 2017 ACC/AHA updated guidelines among Indian population}

\section{Changes in guidelines}

The American Heart Association (AHA) in 2017 updated the hypertension guidelines. According to the latest guidelines, a Systolic Blood Pressure (SBP) of 130 $\mathrm{mmHg}$ or more and a diastolic of $80 \mathrm{mmHg}$ or more is considered as hypertension and needs to be controlled, which is said to be the most important modification. Therefore, persons with SBP of 130-140 $\mathrm{mmHg}$ and/or diastolic $80-90 \mathrm{mmHg}$ are now classified as hypertensive, while they were earlier classified as prehypertensive by Joint National Committee 7 criteria. This represents a large number of people as having elevated BP and warrants lifestyle modifications. The guidelines also emphasize individualized Cardiovascular (CV) risk assessment and to use 10-year CVD risk calculation to decide on treatment threshold. ${ }^{3}$

\section{Implication in Indian population and challenges}

The lowered BP threshold resulted in a $140 \%$ relative increase in the hypertension prevalence in India as per the new ACC/AHA guidelines, which is 3 times higher than the $43 \%$ relative increase reported in the United States. Such an increase in the hypertension prevalence in India is likely to have significant implications for the Indian health system like greater increase in BP values among younger patients, and those from rural and poorest households may exacerbate the existing access-to-care issues in these high-risk subgroups. Hypertension treatment and control rates are already very low in India. ${ }^{4}$

\section{Sympathetic Nerve Activity in Hypertension}

The Sympathetic Nervous System (SNS) constitutes one of the body's main effector systems for maintaining homeostasis at rest, during stress and in disease states. Cannon taught that rapid activation of the SNS preserves the internal environment by producing compensatory and anticipatory adjustments that enhance the likelihood of an individual's survival.

\section{Function}

Because most homeostasis includes the SNS in the range of effectors, alterations in the sympathetic neural outflows accompany virtually all stress responses. Reviewing these alterations requires an integrative understanding of how the processes of norepinephrine synthesis, release, reuptake, vesicular leakage, metabolism, and turnover function together to produce appropriate sympathetic homeostatic responses. ${ }^{5}$

\section{Activity in hypertension}

The SNS plays essential role in the regulatory mechanisms of hypertension, sodium balance, and maintenance of homeostatic state and is an arm of the autonomic nervous system. ${ }^{6}$ Increased SNS activity has been concerned as a primary precursor of hypertension. Imbalances in several neurotransmitters and neuromodulators are present during the development of hypertension, and these directly and indirectly contribute to increased release of noradrenaline onto the postsynaptic targets of the sympathetic nerves. In sodium chloride-sensitive hypertensive subjects, dietary sodium chloride increases SNS activity both directly and indirectly. Bidirectional interactions among the immune system and the SNS also appear to play a role in the development of hypertension. Studies suggest that insulinglucose excess and nitric oxide deficiency may increase the SNS's contribution to some forms of hypertension. ${ }^{7}$

\section{Other associated conditions}

Increased renal sympathetic nerve activity has the potential to drive increased $\mathrm{BP}$ and fluid retention, contributing to the genesis of Cardiovascular Diseases (CVDs), including hypertension and heart failure. ${ }^{8}$

Chronic stimulation of the SNS has the potential to augment risk for the metabolic syndrome through the development of obesity, hyperglycemia, and insulin resistance.

\section{Selective Imidazoline Receptor Agonists (SIRA)}

Stimulation of brain $\alpha 2$-adrenergic receptors is one mechanism for sympathoadrenal suppression but comes at the cost of nonspecific depression of Central Nervous System (CNS) function, including sedation and decreased salivary flow. Evidence is accumulating for a second pathway for pharmacological control of sympathoadrenal outflow, mediated by a novel receptor specific for imidazolines. ${ }^{9}$ Imidazoline receptor agonists control BP effectively with minimal adverse effects of sedation and mental depression that are usually associated with centrally acting antihypertensives. While having a low affinity to the $\alpha 2$-adrenergic receptors, this new 
generation of centrally acting antihypertensive agents is highly selective for the imidazoline receptor. ${ }^{10}$

\section{Mechanism of action}

Imidazoline $\mathrm{I}_{1}$-receptors in the Rostral Ventrolateral Medulla (RVLM) are important for the sympathoinhibitory action of clonidine, rilmenidine, and moxonidine-like antihypertensive drugs. The mechanism by which central antihypertensives lowers BP is a result of activation of both $\alpha 2-\mathrm{AR}$ and $\mathrm{I}_{1}$-IRs in the RVLM. The $\alpha 2-\mathrm{AR}$ agonists directly inhibit pre-sympathetic RVLM neurons, while the $\mathrm{I}_{1}$-IR agonists increase the release of catecholamines in the RVLM. The catecholamines depress pre-sympathetic RVLM neurons by activating $\alpha 2-A R .^{11}$

\section{Moxonidine}

Moxonidine is a second-generation centrally acting antihypertensive drug having selective agonist activity at imidazoline $I_{1}$ receptors and only minor activity at imidazoline $\alpha 2$ adrenoceptors, reduces the activity of the SNS by activating $\mathrm{I}_{1}$ imidazoline receptors in the RVLM. This results in the inhibition of peripheral $\alpha$-adrenergic tone and the decrease of BP due to a fall in Systemic Vascular Resistance (SVR).

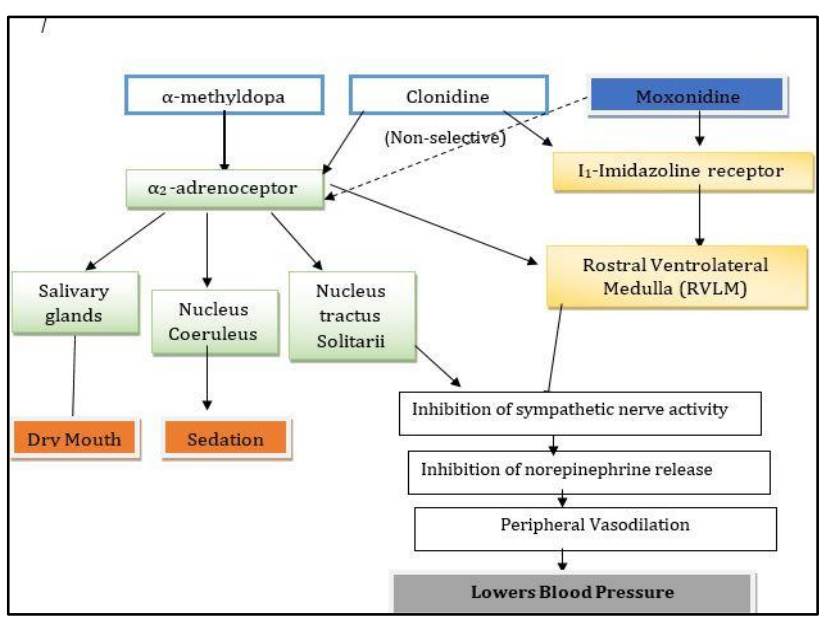

Figure 1: Mechanism of actions of centrally acting agent and moxonidine ${ }^{14}$

Evidences from the larger studies demonstrated that moxonidine acts on heart, a target organ. This effect is achieved through the activation of cardiac $\mathrm{I}_{1}$ imidazoline receptors. Through this mechanism, moxonidine produces clinically relevant sympatholysis, with beneficial effects on overall hemodynamics, and neurohumoral parameters. $^{12}$ Moxonidine produces a pronounced reduction in peripheral vascular resistance without reflex tachycardia, accompanied by reduced plasma norepinephrine concentration and plasma renin activity. Comparisons have shown moxonidine has equal effectiveness in lowering BP like other well-established antihypertensive drugs such as nifedipine, atenolol, or Angiotensin-converting Enzyme inhibitors, with minimal adverse events. Considering its efficacy, safety, and specific effects (e.g., its ability to reduce Left Ventricular Hypertrophy $[\mathrm{LVH}])$, moxonidine meets the criteria satisfied by other currently prescribed antihypertensive drugs. Moxonidine can be recommended as one of the first-line treatment of hypertension in certain situations because of its favourable benefit-to-risk ratio. ${ }^{13}$

\section{Hypertensive efficacy of moxonidine}

\section{Effects of moxonidine in essential hypertension}

A daily dose of $0.2-0.6 \mathrm{mg}$ induces satisfactory BP reduction in patients with mild-to-moderate essential hypertension. In a placebo-controlled, 6-week study of patients with mild-to-moderate hypertension, moxonidine (0.2-0.4 mg o.d.) significantly decreased BP by $19.5 / 11.6$ $\mathrm{mmHg}$ (SBP/DBP, respectively). In elderly patients with resistant hypertension of 60-80 years with poorly controlled BP, moxonidine decreased the mean daytime SBP from 169.2 to $153.8 \mathrm{mmHg}$, and Diastolic Blood Pressure (DBP) from 91.6 to $84.2 \mathrm{mmHg}$. The 24-hr BP readings showed a reduction in the mean SBP from 163.0 to $148.6 \mathrm{mmHg}$ and the mean DBP from 87.2 to 80.2 $\mathrm{mmHg}$ significantly $(\mathrm{p}=0.013) .{ }^{19,20}$

\section{In obese, non-controlled hypertensive patients}

Abellan $\mathrm{J}$, et al, in an interventional study, added moxonidine to non-controlled, hypertensive, obese subjects totaling 112 patients (61 males and 51 females). The reduction in the mean SBP after moxonidine treatment and during the 6-month duration was 23.01 $\mathrm{mmHg}$ (14\% of the baseline value). The decrease in DBP was $12.9 \mathrm{mmHg}$ (13.5\% of the baseline value). For the whole group, the mean systolic and diastolic pressures were $158.5 \pm 10.6$ and $95.1 \pm 9 \mathrm{mmHg}$, respectively, at baseline vs. $135.5 \pm 11.6$ and $82.2 \pm 5.8 \mathrm{mmHg}$ at the end of the study. In terms of BP control, 96 patients $(86 \%)$ achieved DBP control at the end of the study; $70(63 \%)$ of them had SBP adequately controlled, and $54(48 \%)$ were seen to have adequately controlled the 2 BP components after 6 months.

Body weight decreased from $88.19 \pm 12.09 \mathrm{~kg}$ (baseline) to $84.9 \pm 11.5 \mathrm{~kg}$ (6-month) $(\mathrm{p}<0.01)$. The Body Mass Index (BMI) was also seen to decrease from 33.6 to 32.3 $\mathrm{kg} / \mathrm{m}^{2}(\mathrm{p}<0.01)$.

\section{Antihypertensive efficacy and safety of moxonidine as a combination therapy}

The use of the combination of both moxonidine and hydrochlorothiazide for 8 weeks led to a $27 / 16 \mathrm{mmHg}$ fall in BP. ${ }^{22}$ In patients with metabolic syndrome presenting with moderate hypertension, ramipril+moxonidine combination therapy after 12 weeks normalized BP in $88 \%$ of the patients compared to BP normalization in $40 \%$ and $44 \%$ on monotherapies with ramipril or moxonidine, respectively. ${ }^{23}$ 
Table 1: Dose range and pharmacokinetics of central sympatholytic drugs. ${ }^{15-18}$

\begin{tabular}{|c|c|c|c|c|c|c|c|c|c|}
\hline Drug & $\begin{array}{l}\text { Total } \\
\text { dose } \\
\text { Range, } \\
(\mathrm{mg} / \mathrm{d})\end{array}$ & $\begin{array}{l}\text { Doses } \\
\text { Per } \\
\text { day }\end{array}$ & $\begin{array}{l}\text { T- } \\
\max \\
(h r s)\end{array}$ & $\begin{array}{l}\text { Half- } \\
\text { life } \\
\text { (hrs) }\end{array}$ & $\begin{array}{l}\text { Renal } \\
\text { Elimination } \\
(\%)\end{array}$ & $\begin{array}{l}\text { Volume } \\
\text { of } \\
\text { Distribution } \\
\left(1 / \mathbf{k g}^{16}\right.\end{array}$ & $\begin{array}{l}\text { Absorption } \\
(\%)^{16}\end{array}$ & $\begin{array}{l}\text { Metabolic } \\
\text { Effects }^{17}\end{array}$ & $\begin{array}{l}\text { Adverse } \\
\text { Effects }^{18}\end{array}$ \\
\hline Clonidine & $0.2-1.2$ & $2-3$ & $1-4$ & $6-16$ & $40-60$ & 2.0 & $75-100$ & No & $\begin{array}{l}\text { Drowsiness, } \\
\text { Sedation, } \\
\text { Lethargy, } \\
\text { Dry mouth }\end{array}$ \\
\hline Methyldopa & $\begin{array}{l}250- \\
2000\end{array}$ & 2 & $2-4$ & $1-2$ & 70 & 0.6 & 25 & - & $\begin{array}{l}\text { Restlessness, } \\
\text { Sweating, } \\
\text { Anxiety, } \\
\text { tremor, } \\
\text { Palpitations, } \\
\text { And } \\
\text { headache }\end{array}$ \\
\hline Moxonidine & $0.2-0.6$ & $1-2$ & $\begin{array}{l}1.0- \\
1.5\end{array}$ & $2-3$ & $50-75$ & 3.0 & $80-90$ & Yes & $\begin{array}{l}\text { Dry mouth } \\
\text { Is the only } \\
\text { adverse } \\
\text { effect }\end{array}$ \\
\hline Rilmenidine & $1-2$ & 1 & 1.7 & 8.5 & $52-93$ & $315-325$ & 100 & No & Dry mouth \\
\hline
\end{tabular}

\section{Pleiotropic benefits of moxonidine}

\section{Influence of moxonidine on target organ protection and metabolism}

Sanjuliani, et al., showed that after 24 weeks of moxonidine treatment, plasma arterial adrenaline and noradrenaline were significantly reduced. This fact confirms the decrease of plasma catecholamines, and moreover, proves the action of the drug in conditions of sympathetic overactivity. ${ }^{24}$ A double-blind, placebocontrolled, crossover study demonstrated that moxonidine reduces exercise and mental stress-induced SNS activation and seems to be considered as an alternative to b-adrenoceptor blockers in combination therapy, when patients are bothered by the exercise limitations of badrenoceptor blockers. ${ }^{25}$

The study of Krespi, et al., suggests that in hypertensive patients with microalbuminuria, moxonidine reduces urine albumin excretion, thrombomodulin, and Plasminogen Activator Inhibitor-1 (PAI-1) levels. These results demonstrate an effect on renal function and endothelial homeostatic mechanisms. ${ }^{26}$ Also, a 3-year trial showed that treatment with standard antihypertensive therapy and adjunctive moxonidine in patients with advanced renal failure was predicted to reduce the number of new end-stage renal disease cases compared to adjunctive nitrendipine. The model showed that adjunctive moxonidine seems to increase life-years lived. ${ }^{27}$

\section{Metabolic syndrome}

Metabolic syndrome is a cluster of metabolic abnormalities that includes hypertension, central obesity, insulin resistance, and atherogenic dyslipidemia and strongly associated with a greater risk of developing ASCVD. ${ }^{28}$ Currently, global estimate of metabolic syndrome among the adult population is around $20-25 \%$ with a rapid increasing rate in South Asian countries particularly in India leading to increased morbidity and mortality due to CVD and Type 2 Diabetes Mellitus (T2DM) ${ }^{29}$ Metabolic syndrome confers a 5-fold increase in the risk of T2DM and 2-fold the risk of developing CVD over the next 5-10 years with a 2-to 4-fold increased risk of stroke and 3-to 4-fold increased risk of MI. ${ }^{30}$

\section{Pathophysiology of metabolic syndrome}

AT2 =Angiotensin II type 2 receptor; $\mathrm{CRP}=\mathrm{C}$-reactive protein; IL-6 =Interleukin 6; LOX =Lectin-like oxidized low-density lipoprotein; RAAS=Renin-angiotensinaldosterone system; ROS =Reactive oxygen species; TNF $=$ Tumor necrosis factor. ${ }^{28}$

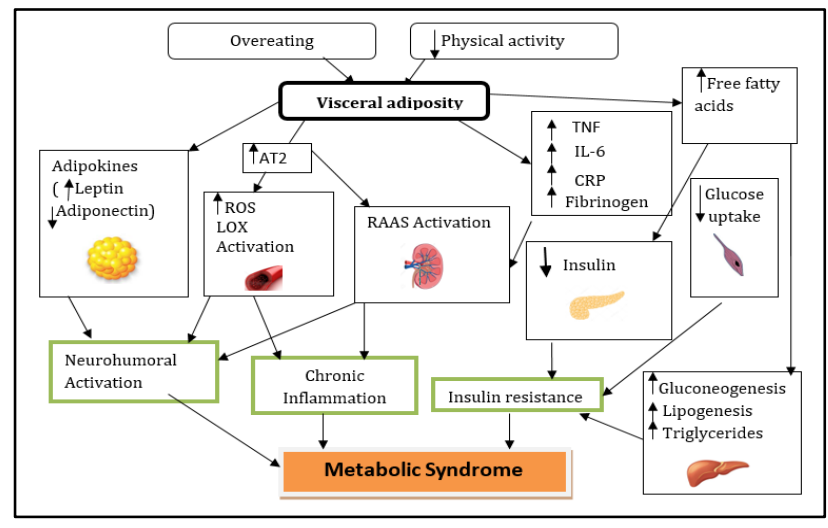

Figure 2: Pathophysiological mechanisms in metabolic syndrome. 
Importance of hypertension management in metabolic syndrome

A very high prevalence of metabolic syndrome in the hypertensive population is observed in study of more than 19,000 hypertensive patients attending primary care centers in Spain, where, more than $40 \%$ of people were present with metabolic syndrome using the original ATPIII definition. The presence of metabolic syndrome is accompanied by a 3-to 6-fold increase in the risk of developing T2D and also enhances the risk of developing chronic kidney disease (albuminuria and/or a diminished estimated Glomerular Filtration Rate [GFR]. Hypertension associated with metabolic syndrome has pathophysiologic characteristics that provide clinical challenges as well as opportunities for successful therapeutic interventions. ${ }^{31}$

\section{Challenges in management of hypertension in metabolic syndrome}

- The syndrome is not a discrete entity known to be caused by a single factor. Moreover, it shows considerable variation in the components among different individuals. This variation is even greater among different racial and ethnic groups. ${ }^{32}$

- In hypertensive patients with metabolic syndrome, procedures to diagnose hypertension should be more extensive than usual because of the higher prevalence of multiple organ damage and increased levels of inflammatory markers.

- Lack of specific intervention trials in metabolic syndrome prevents any firm recommendation to be given on whether lifestyle modifications should be associated with antihypertensive drug treatment in non-hypertensive and non-diabetic patients with $\mathrm{MS}^{33}$

\section{Role of centrally acting antihypertensive drugs in patients with hypertension with metabolic syndrome}

Antihypertensive treatment with a centrally acting sympatholytic agent that targets common underlying pathophysiologic pathways is a safe and effective treatment strategy with potential additional benefits in regard to metabolic disturbances frequently encountered in hypertensive populations. ${ }^{34}$

Traditional centrally acting antihypertensives have been associated with a high incidence of adverse effects and are no longer recommended as first-line therapy. With methyldopa, a centrally acting alpha (2)-agonist, although unpredictable idiosyncratic or hypersensitivity reactions are uncommon, these include hepatitis, myocarditis, and haemolytic anemia. Less serious problems such as abnormal liver function tests, positive Coombs test, druginduced fever, and pancreatitis also occur. Central sideeffects include drowsiness, fatigue, lethargy, sedation, depression, psychotic reactions, nasal stuffiness, impotence, and exacerbation of parkinsonism. Clonidine acts primarily as an alpha (2)-agonist but also acts as an agonist at imidazoline receptors in the RVLM but is considerably less well-tolerated in comparative trials. The principal adverse effects of clonidine are drowsiness, sedation, lethargy, and dry mouth. Reserpine acts primarily by depleting central catecholamine neurotransmitter stores; its central side-effects of sedation, nasal stuffiness, and severe depression are now considered so undesirable that the drug is seldom prescribed. Rilmenidine acts selectively and has very little central alpha (2)-agonist activity. ${ }^{18}$

\section{Moxonidine in the management of hypertension and metabolic syndrome}

Moxonidine reduces BP in patients with metabolic syndrome while simultaneously reducing body weight in obese patients, as it has been shown in the postmarketing surveillance study CAMUS.35 Furthermore, moxonidine is used in the treatment of obese patients with metabolic syndrome because this antihypertensive agent reduces leptin levels in plasma and reduces weight in obese patients through the action of the SNS. ${ }^{12}$

Also, a multicentric, prospective, randomized, open-label study showed that moxonidine improves insulin sensitivity in response to glucose challenge in patients with evidence of metabolic syndrome. ${ }^{34}$

\section{DISCUSSION}

While BP reduction is the primary goal of antihypertensive therapy, potential effects on metabolic parameters also need to be taken into account. ${ }^{34}$

Although centrally acting antihypertensive drugs have a proven efficacy in controlling or decreasing BP, they are no longer widely used because of the relative high incidence of adverse effects. Most central side-effects occurring with these drugs are mediated by the $\alpha 2$-receptor. Moxonidine is an imidazoline receptor agonist that is highly selective for the $\mathrm{I}_{1}$-imidazoline receptor with little effect at the central $\alpha 2$ receptor. Moxonidine has been shown to diminish sympathetic activity, as measured by norepinephrine, epinephrine, and plasma renin activity. Clinical studies have documented efficacy of moxonidine as an antihypertensive agent. Most patients' BP was satisfactorily controlled with a dose between 0.2 and $0.4 \mathrm{mg}$ per day. Comparative studies with most other antihypertensive drug classes such as clonidine, diuretics, alpha-blockers, beta-blockers, calcium antagonists, and ACE inhibitors document similar BP control with moxonidine as with other agents. Specifically, by using 24-hr ambulatory BP monitoring, BP control was found to be similar with moxonidine and enalapril. ${ }^{36}$ Moxonidine (0.2-0.4 mg once daily) for 6 months, either as monotherapy or as adjunctive therapy to current antihypertensive treatment in patients with uncontrolled essential hypertension meeting criteria for metabolic syndrome, was associated with: (i) improvement in control of BP, (ii) neutral or beneficial trends in a range of metabolic indices including lipid fractions and fasting plasma glucose 
and weight loss which has clearly been associated with improved $\mathrm{CV}$ and other outcomes, suggesting that moxonidine may have additional beneficial effects beyond $\mathrm{BP}$ reduction, particularly in overweight or obese hypertensive subjects or those with the metabolic syndrome. In this context, the average reduction in body weight of $2.1 \mathrm{~kg}$ in patients treated with moxonidine replicates that early treatment of moxonidine has benefits in population with metabolic syndrome. ${ }^{34}$

The use of antihypertensive, for an aggressive BP control, in addition to a healthy lifestyle in patients with stage 2 hypertension and individualization of the treatment for a reduction of BP are the requirements of the hour. Treatment aim to achieve the target BP need not be very strict, it should be a less stringent one. There is no sufficient clinical data to set the target $\mathrm{BP}$ in diabetic hypertensives as $130 / 80 \mathrm{mmHg}$, as even the current ADA 2018 guidelines suggest 140/90 $\mathrm{mmHg}$ as the suggested target.

Metabolic syndrome is a very common disease with repercussion on sympathetic overactivity. Metabolic syndrome is going to rise as major problem of our country with its increase in the affluence, changes in lifestyle, and less physical activity. Sympathetic overstimulation is chiefly responsible for causation of obesity, insulin resistance, and hypertension, thereby resulting in the constellation of metabolic syndrome.

In clinical practice, there is lot more experience about the use of moxonidine as there are a number of trials comparing moxonidine and clonidine, which showed that moxonidine is as effective as clonidine. Additionally, moxonidine causes less dryness of mouth (about 30-40\% patients in current clinical practice) and less incidence of postural hypotension compared to clonidine. Moxonidine, besides alpha and beta-blocking, has got another 4 actions - action on leptin, metabolic syndrome, satiety center, and liver. Edema, which is commonly seen in most of the renal patients, makes it often confounding whether it is due to renal deterioration or due to the Calcium Channel Blocker (CCB). If there is a rise in creatinine, moxonidine is a very good add-on therapy (recommended if the rise in creatinine is by more than $25 \%$ from the baseline) to either an ACE inhibitor or an ARB in diabetic or non-diabetic. In addition, moxonidine is also a good add-on to a diuretic if the patient's BP is not controlled and if it is refractory. Moxonidine has favourable benefit as opposed to beta-blockers which causes worsening of lipid profile.

Funding: No funding sources

Conflict of interest: None declared

Ethical approval: Not Required

\section{REFERENCES}

1. Makridakis S, DiNicolantonio JJ. Hypertension: empirical evidence and implications in 2014. Open Heart. 2014 Jul 1;1(1):e000048.
2. Shere A, Eletta O, Goyal H. Circulating blood biomarkers in essential hypertension: a literature review. J Lab Precis Med. 2017;2(99):1-11.

3. Narang R, Srikant S. Implications of 2017 hypertension guidelines for Indian patients. J Pract Cardiovasc Sci. 2018;4(1):3-5.

4. enkateshmurthy NS, Geldsetzer P, Jaacks LM, Prabhakaran D. Implications of the new American College of Cardiology Guidelines for hypertension prevalence in India. JAMA Int Med. 2018 Oct 1;178(10):1416-8.

5. Goldstein DS, Eisenhofer G. Sympathetic Nervous System Physiology and Pathophysiology in Coping with the Environment. 2011. First published: 01 January 2011.

6. Moreira MC, Pinto IS, Mourão AA, Fajemiroye JO, Colombari E, Reis AA, et al. Does the sympathetic nervous system contribute to the pathophysiology of metabolic syndrome?. Frontiers Physiol. 2015 Aug $25 ; 6: 234$.

7. Wyss JM. The role of the sympathetic nervous system in hypertension. Curr Opinion Nephrol Hypert. 1993;2:265-73.

8. Barrett CJ. Renal sympathetic nerves-what have they got to do with cardiovascular disease?. Experimental physiology. 2015 Apr 1;100(4):359-65.

9. Ernsberger P, Haxhiu MA, Graff LM, et al. A Novel Mechanism of Action for Hypertension Control: Moxonidine as a Selective Ii-Imidazoline Agonist. Cardiovas Drugs Ther. 1994;8(1):27-41.

10. Yu A, Frishman WH. Imidazoline receptor agonist drugs: a new approach to the treatment of systemic hypertension. J Clin Pharmacol. 1996 Feb;36(2):98111.

11. Nikolic $\mathrm{K}$ and Agbaba D. Imidazoline Antihypertensive Drugs: Selective $\mathrm{I}_{1}$-Imidazoline Receptors Activation. Cardiovascular Therapeutics. 2012;209-16.

12. Karlafti EF, Hatzitolios AI, Karlaftis AF, Baltatzi MS, Koliakos GG, Savopoulos CG. Effects of moxonidine on sympathetic nervous system activity: An update on metabolism, cardio, and other targetorgan protection. J PharmBioallied Sci. 2013;5(4):253-6.

13. Ollivier JP, Christen MO. $\mathrm{I}_{1}$-imidazoline-receptor agonists in the treatment of hypertension: an appraisal of clinical experience. J Cardiovasc Pharmacol. 1994;24(1):S39-48.

14. Zwieten V. Centrally acting antihypertensives: a renaissance of interest: mechanisms and haemodynamics. J hypertension. 1997;15(1):S3-8.

15. Vongpatanasin W, Kario K, Atlas SA, Victor RG.et al. Central Sympatholytic Drugs. J Clin Hypertension. 2011;13(9):658-61.

16. Sica DA. Centrally Acting Antihypertensive Agents: An Update. J Clin Hypertension. 2007;9(5):399-405.

17. Schachter M. Metabolic effects of moxonidine and other centrally acting antihypertensives. Diabetes Obes Metab. 1999;1(6):317-22. 
18. Webster J, Koch HF. Aspects of tolerability of centrally acting antihypertensive drugs. J Cardiovasc Pharmacol. 1996;27(3):S49-54.

19. Farsang C. Moxonidine: Clinical Profile. J Clin Basic Cardiol. 2001;4(3):197.

20. Martin U, O' Mahony D. Use of moxonidine in elderly patients with resistant hypertension. J Clin Pharmacy and Therapeut. 2005;30(5):433-7.

21. Abellán J, Leal $\mathrm{M}$, Hernández-Menárguez $\mathrm{F}$, García-Galbis JA, Martínez-Pastor A, de Vinuesa SG, et al. Efficacy of moxonidine in the treatment of hypertension in obese, noncontrolled hypertensive patients. Kidney Int Suppl. 2005;(93):S20-4.

22. Prichard BNC, Graham BR. The use of moxonidine in the treatment of hypertension. $\mathrm{J}$ Hypert. 1997;15(1):S47-55.

23. Uzokov JK, Alyavi AL, Akhmedov IY, Karimov BB, Rakhmonkulov EJ. Efficacy and safety of combined antihypertensive therapy with ramipril and moxonidine in patients with metabolic syndrome. J Am Society Hypert. 2016;10(4S):e39-e55.

24. Sanjuliani AF, de Abreu VG, Braga JU, et al. Effects of Moxonidine on the Sympathetic Nervous System, Blood Pressure, Plasma Renin Activity, Plasma Aldosterone, Leptin, and Metabolic Profile in Obese Hypertensive Patients. J Clin Basic Cardiol. 2004;7(1):19-25.

25. Wenzel RR, Mitchell A, Siffert W, Bührmann S, Philipp T, Schäfers RF. The $\mathrm{I}_{1}$-imidazoline agonist moxonidine decreases sympathetic tone under physical and mental stress. Br J Clin Pharmacol. 57(5):545-51.

26. Krespi PG, Makris TK, Hatzizacharias AN, Triposkiadis P, Tsoukala C, Kyriaki D, et al. Moxonidine Effect on Microalbuminuria, Thrombomodulin, and Plasminogen Activator Inhibitor-1 Levels in Patients with Essential Hypertension. Cardiovas Drugs Ther. 1998;12(5):463-7.

27. Littlewood KJ, Greiner W, Baum D, et al. Adjunctive treatment with moxonidine versus nitrendipine for hypertensive patients with advanced renal failure: a cost-effectiveness analysis. BMC Nephrol. 2007;8(1):9.

28. Rochlani Y, Pothineni NV, Kovelamudi S, Mehta JL. Metabolic syndrome: pathophysiology, management, and modulation by natural compounds. Ther Adv Cardiovasc Dis. 2017; 11(8):215-25.

29. Singh J, Rajput M, Rajput R. Prevalence and Predictors of Metabolic Syndrome in a North Indian Rural Population: A Community Based Study. J Glob Diabetes Clin Metab. 2016;1(2):1-5.

30. Kaur J. A Comprehensive Review on Metabolic Syndrome. Cardiol Research Practice. 2014;1-21.

31. De la Sierra A. Metabolic Syndrome in Hypertension - Treatment Challenges and Goals. Eur Cardiol. 2009:5(2):40-3.

32. Grundy SM, Cleeman JI, Daniels SR, Donato KA, Eckel RH, Franklin BA, et al. Diagnosis and Management of the Metabolic Syndrome An American Heart Association/National Heart, Lung, and Blood Institute Scientific Statement. Circulation. 2005 Oct 25;112(17):2735-52.

33. Makaryus N, Akhrass P, Mcfarlane S. Treatment of Hypertension in Metabolic Syndrome: Implications of Recent Clinical Trials. Curr Diab Rep. 2009 Jun;9(3):229-37.

34. Chazova I, Almazov VA, Shlyakhto E. Moxonidine improves glycaemic control in mildly hypertensive, overweight patients: a comparison with metformin. 2006;8(4):456-65.

35. Sharma AM, Wagner T, Marsalek P. Moxonidine in the treatment of overweight and obese patients with the metabolic syndrome: a postmarketing surveillance study. J Human Hypert. 2004 Sep;18(9):669.

36. Messerli F. Moxonidine: a new and versatile antihypertensive. J Cardiovasc Pharmacol. 2000;35(4):S53-6.

Cite this article as: Shetty S, Bhoraskar A, Mohan JC, Chafekar D, Tripathi K, Shivlingam M, et al. Selective Imidazoline Receptor Agonists: redefining the role of centrally acting agents in management of hypertension. Int J Adv Med 2019;6:1688-94. 